\title{
INFLUÊNCIA DA ADIÇÃO DE EXTRATO DE LEVEDURA NA PRODUÇÃO DE ÁCIDO LÁTICO POR BACTÉRIAS LÁTICAS EM MEIO HIDROLISADO DE BATATA
}

\author{
M. L. F. ALVES ${ }^{1}$, R. S. LEAL ${ }^{1}$, C. A. REIS ${ }^{1}$, O.L.M. BERNAL ${ }^{1}$, J. G. L. F. ALVES ${ }^{1}$, \\ ${ }^{1}$ Universidade Federal de Lavras, Departamento de Ciência dos Alimentos \\ E-mail para contato: mariliana_luiza@hotmail.com,jlembi@dca.ufla.br
}

\begin{abstract}
RESUMO - As bactérias láticas (BAL) possuem complexas exigências nutricionais para seu desenvolvimento e produzem o ácido lático (AL) como produto final. A batata, rica em amido e vitaminas, é uma potencial matéria-prima a ser utilizada em processos fermentativos, possui grande importância no agronegócio brasileiro e apresenta perdas significativas na sua cadeia produtiva. Assim, esta pesquisa teve por objetivo avaliar a produção de AL por 5 espécies de BAL estudando o efeito do enriquecimento do meio de fermentação com $5 \%$ de extrato de levedura (EL) utilizando meios hidrolisados de batata. As fermentações foram conduzidas sem agitação em erlenmeyers $\left(37^{\circ} \mathrm{C} / 96 \mathrm{~h}\right)$ e a quantificação de AL foi realizada por CLAE. As maiores produções foram observadas com as espécies do gênero Lactobacillus em meios adicionados de EL. Contudo, a produção de AL por Enterococcus faecalis, não mostrou ser afetada pelo enriquecimento do meio, mantendo a mesma produtividade $\left(0,05 \mathrm{~g} \cdot \mathrm{L}^{-1} \cdot \mathrm{h}^{-1}\right) \mathrm{em}$ ambas as condições e boa produção de ácido lático $(5,2 \mathrm{~g} / \mathrm{L})$. Tal resultado pode beneficiar economicamente a produção de AL, uma vez que reduz os custos oriundos do enriquecimento do meio fermentativo.
\end{abstract}

\section{INTRODUÇÃO}

As bactérias láticas (BAL) constituem um grupo de organismos heterotróficos amplamente conhecidos e de extrema importância comercial. Costumam apresentar complexas exigências nutricionais para o seu desenvolvimento (Reddy et al., 2008) e são unidas por diversas características morfológicas, metabólicas e fisiológicas (Salminen et al., 2004). As BAL obtêm energia, por meio da fermentação de açúcares e o ácido lático (AL) é o principal produto final do metabolismo da glicose pela via homofermentativa (Reddy et al., 2008). Visando um maior rendimento na produção do AL, alguns pesquisadores têm suplementado o meio de cultivo com fontes de nitrogênio (Altaf et al., 2007; Lima et al., 2009) que possam atender às necessidades nutricionais das BAL e, consequentemente, aumentar a produção. Dentre as fontes de nitrogênio utilizadas, está o extrato de levedura (Mi-Young et al., 2003; Oliveira et al., 2009).

O ácido lático (AL) é um ácido orgânico produzido principalmente por fermentação ou por síntese química (Vijayakumar et al., 2008). Sua obtenção por fermentação microbiana apresenta vantagens significativas, como o emprego de recursos renováveis ricos em nutrientes, como a batata (John et al., 2007). A batata é um tubérculo muito consumido em 
todos os continentes (Pereira, 2008), é rica em amido e possui alto valor nutricional. No Brasil, o maior estado produtor de batata é Minas Gerais (Instituto Brasileiro de Geografia e Estatística, 2013). Entretanto, a bataticultura brasileira apresenta problemas na sua cadeia produtiva, pelas rigorosas exigências do consumidor quanto à aparência externa do tubérculo, fazendo com que parte significativa de toda a produção nacional seja descartada com frequência (Tavares, 2009). Neste contexto, o objetivo do presente estudo foi avaliar a produção de AL por 5 espécies de BAL estudando o efeito do enriquecimento do meio de fermentação com 5\% de extrato de levedura (EL) utilizando meios hidrolisados de batata.

\section{MATERIAIS E MÉTODOS}

\subsection{Obtenção e Manutenção dos Microrganismos}

Os microrganismos utilizados foram cedidos pela Fundação Oswaldo Cruz (FioCruz/RJ) e de acordo com o acervo disponível, foram selecionadas as espécies com produção de L(+) ácido lático já relatada: Enterococcus durans (ATCC 6056), E. faecalis (ATCC 29212), Lactobacillus plantarum (ATCC 10012), L. rhamnosus (ATCC 9595) e Streptococcus mutans (ATCC 25175). Uma vez que os microrganismos foram adquiridos na forma liofilizada, uma etapa de ativação $\left(37^{\circ} \mathrm{C} / 48 \mathrm{~h}\right.$ ) em caldo MRS (Man, Rogosa e Sharpe - Himédia $\left.{ }^{\circledR}\right)$ estéril $\left(121^{\circ} \mathrm{C} / 15 \mathrm{~min}\right)$ foi necessária. A temperatura utilizada é considerada ótima para as BAL (Salminen et al., 2004). Subsequente à ativação das bactérias foi realizada a propagação dos microrganismos e a preparação da cultura estoque em glicerol.

\subsection{Preparo do Inóculo e do Meio de Fermentação}

Com base na correlação absorbância e número de células viáveis, estabelecida por meio das curvas de crescimento, determinou-se os volumes de inóculo a ser transferido para o meio de fermentação: $1 \%$ v/v (L. plantarum e L. rhamnosus) e $10 \%$ v/v (E. durans, E. faecalis e $S$. mutans) ambos correspondente a uma contagem entre $10^{7}$ e $10^{8}$ UFC.mL ${ }^{-1}$ para início da fermentação

Batatas da espécie Solanum tuberosum ssp. tuberosum, cultivar Ágata, foram lavadas, secas, descascadas, picadas e trituradas em liquidificador industrial (cerca de $5 \mathrm{~min}$ ). A polpa foi armazenada em sacos hermeticamente fechados (1 $\mathrm{kg} / \mathrm{saco})$ em temperatura de congelamento para posterior utilização. A obtenção do hidrolisado, se deu primeiramente pela homogeneização de $330 \mathrm{~g}$ de polpa de batata em $670 \mathrm{~mL}$ de água destilada. O volume total da mistura sofreu processo de hidrólise enzimática do amido realizado em duas etapas, utilizando as enzimas $\alpha$-amilase e amiloglicosidase, conforme a metodologia descrita por Pavlak et al.,(2011). Concluída a etapa de hidrólise, a mistura foi arrefecida e acrescida ou não de $5 \%$ (v/v) de EL. O pH foi ajustado para a faixa ótima de atuação das BAL, entre 5 e 7 (Vijayakumar et al., 2008), o mosto foi esterilizado $\left(121^{\circ} \mathrm{C} / 15 \mathrm{~min}\right)$, resfriado e adicionado de inóculo (1\% ou 10\%). As fermentações foram conduzidas em estufa BOD sem agitação a $37{ }^{\circ} \mathrm{C} / 96 \mathrm{~h}$, dentro de erlenmeyers vedados com algodão. Foram retirados do mosto aproximadamente $15 \mathrm{~mL}$ de amostra a cada $12 \mathrm{~h}$. As amostras foram centrifugadas $(2260 \mathrm{~g} / 30$ min), o sedimentado foi descartado e o sobrenadante foi congelado e armazenado para análises posteriores. Todos os processos fermentativos foram realizados em triplicata. As enzimas utilizadas nesta pesquisa foram doadas pela empresa Romerlabs 


\subsection{Metodologia Analítica}

As análises realizadas foram executadas em triplicata, e seus resultados expressam a média desses valores.

Caracterização da matéria-prima: A umidade e a composição centesimal da polpa de batata foram determinadas conforme a AOAC International (2012) e o Instituto Adolfo Lutz (2008), e o teor de amido seguiu a metodologia de Somogyi modificado por Nelson (1944).

Determinação do $\mathrm{pH}$ e acidez titulável: $\mathrm{O} \mathrm{pH}$ das amostras foram medidos com auxílio de potenciômetro digital de bancada. A acidez titulável foi determinada conforme a AOAC International, (2012). O ponto de viragem da titulação se deu quando a amostra atingia $\mathrm{pH}$ próximo a 8,3 (Plata-Oviedo, 1998).

Quantificação e produtividade de AL: As amostras foram filtradas através de filtros de seringa $(0,22 \mu \mathrm{m}$ de porosidade e $25 \mathrm{~mm}$ de diâmetro) e diluídas com água deionizada antes da análise. Foi utilizado cromatógrafo (Shimadzu) equipado com detector de condutividade (CDD-6A), polaridade +, uma pré-coluna SHIM-PACK SPR-H(G) $(50 \mathrm{~mm} \times 7.8 \mathrm{~mm})$ e duas colunas em série SHIM-PACK SPR-H $(250 \mathrm{~mm} \times 7.8 \mathrm{~mm})$. A fase móvel foi uma mistura de $16 \mathrm{mM}$ de Bis-Tris, $4 \mathrm{mM}$ de ácido p-tolueno sulfônico e $100 \mu \mathrm{M}$ de EDTA; com fluxo de 0,8 $\mathrm{mL} / \mathrm{min}$. O volume injetado da amostra foi de $20 \mu \mathrm{L}$ e a temperatura de injeção $45^{\circ} \mathrm{C}$. A quantificação do AL foi determinada pela comparação dos tempos de retenção dos picos e curva de calibração de padrão de $\operatorname{AL}\left(\operatorname{Sigma}^{\circledR}\right)$. A produtividade do processo se deu pela divisão de AL produzido e o tempo de fermentação (Oliveira et al., 2009).

Contagem de células viáveis: Utilizou-se plaqueamento em profundidade ("pour plate"). As amostras foram diluídas decimalmente em água peptonada $0,1 \%(\mathrm{~m} / \mathrm{v})$ e uma alíquota de 1 $\mathrm{mL}$ de cada diluição foi distribuída em placas de petri e homogeneizada no meio de cultura ágar MRS (Himédia ${ }^{\circledR}$ ). As placas foram incubadas a $37^{\circ} \mathrm{C} / 72 \mathrm{~h}$ (Tebaldi et al., 2007).

\section{RESULTADOS E DISCUSSÃO}

A composição química da polpa de batata utilizada nesse estudo para amido, cinzas, fibra, lipídeos, proteína e umidade foi de 8,$17 ; 0,72 ; 0,6 ; 0,14 ; 2,25$ e $85,65 \% \mathrm{~m} / \mathrm{m}$, respectivamente é próxima as relatadas por outros autores (Evangelista et al., 2011; Núcleo de Estudos e Pesquisas em Alimentos, 2006).

\subsection{Estudo Cinético do pH e Acidez das Fermentações}

$\mathrm{O}$ pH inicial dos meios de fermentativos estava dentro do intervalo ótimo para atividade metabólica das BAL, entre 5 e 7 (Vijayakumar et al. 2008), proporcionando condições adequadas para a produção do AL. O menor pH final em meio sem EL foi observado para $E$. faecalis, L. rhamnosus e L. plantarum, entre 3,11 e 3,33. S. mutans obteve a menor variação de $\mathrm{pH}$, com valor final de 4,26, seguido de E. durans $(3,75)$, como mostra a Figura 1a. No decorrer do processo fermentativo, as espécies do gênero Lactobacillus acompanhados por $E$. faecalis mostraram aumento gradativo na produção de ácidos, enquanto que as demais produziram pouco ácidos orgânicos. As maiores produções foram obtidas por E. faecalis 
$(9,45 \%)$, L. plantarum $(9,36 \%)$ e L. rhamnosus $(7,95 \%)$, que atingiram após 96 horas, acidez final de 12,24, 12,00 e 9,93\%, respectivamente (Figura 1b).
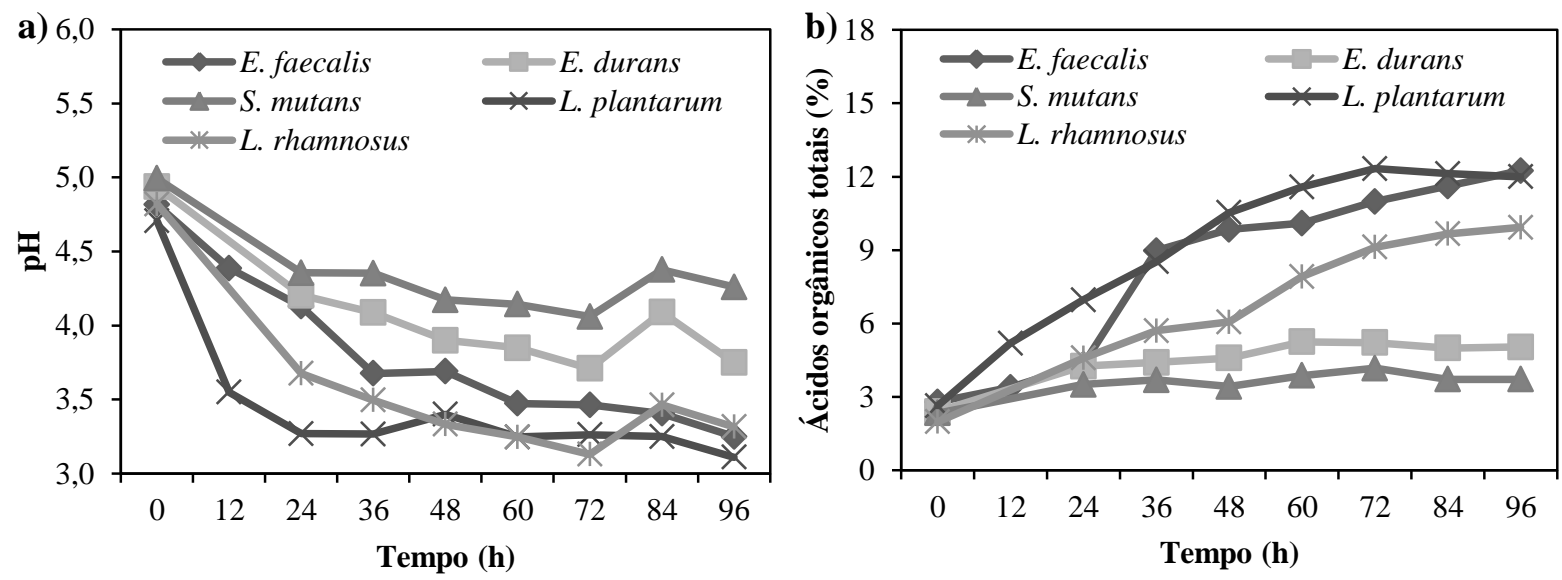

Figura 1 - Cinética do pH (a) e da produção de ácidos orgânicos totais (b) em meios fermentativos sem extbirato de levedura.

Nos meios de fermentação com EL (Figura 2), as maiores reduções de pH também ocorreram nos meios com E. faecalis, L. rhamnosus e L. plantarum, sendo que o último atingiu valor final de 3,79 . O pH final de E. durans $(4,41)$ e $S$. mutans $(4,33)$, não mostraram diferença estatisticamente significativa entre si $(\mathrm{p}<0,05)$. Nas demais espécies o pH final oscilou entre 3,79 e 3,9. Independentemente do microrganismo utilizado, o valor do $\mathrm{pH}$ se estabilizou após $36 \mathrm{~h}$ de fermentação (Figura 2a). A Figura $2 \mathrm{~b}$ mostra que as maiores produções de ácidos orgânicos foram obtidas por L. rhamnosus $(15,63 \%)$, L. plantarum $(15,09 \%)$, E. faecalis $(10,56 \%)$. Comportamento diferente do apresentado nos meios sem EL (Figura 1b), onde E. faecalis obteve a maior produção $(9,45 \%)$, seguida por e L. plantarum $(9,36 \%)$ e L. rhmanosus $(7,95 \%)$.
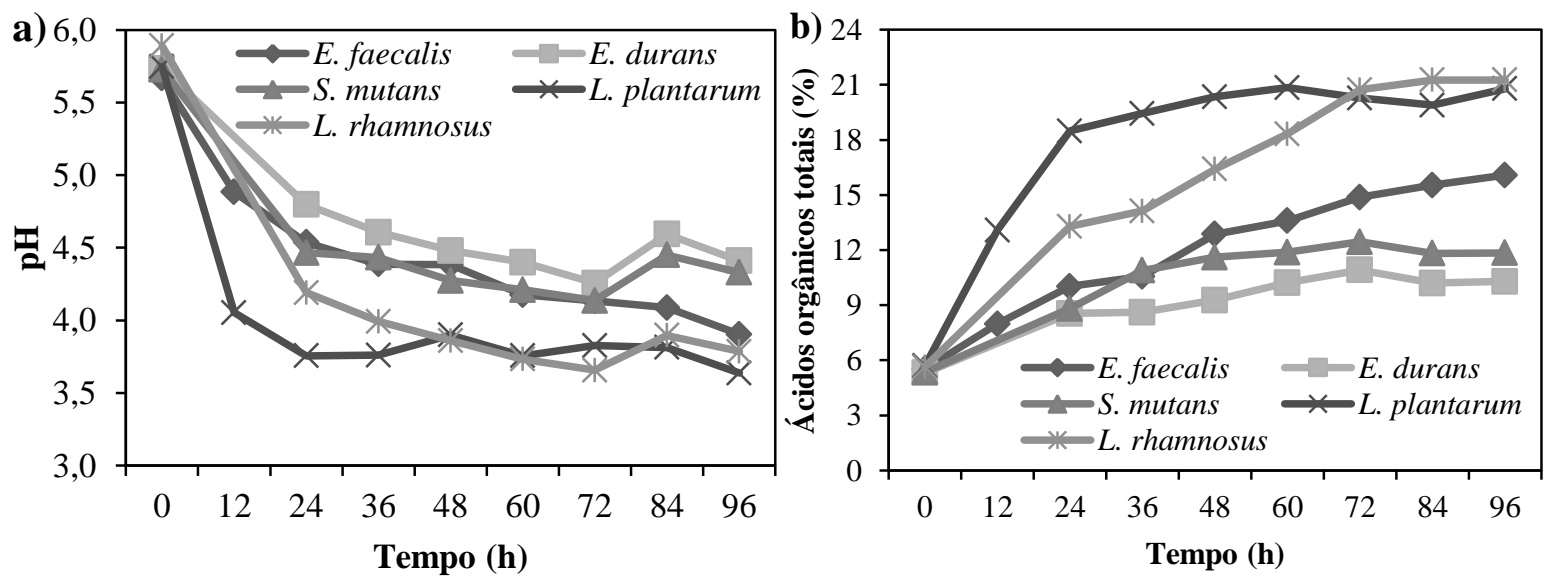

Figura 2 - Cinética do pH (a) e da produção de ácidos orgânicos totais (b) em meios fermentativos com extrato de levedura.

$\mathrm{O} \mathrm{pH}$ da fermentação pode influenciar diretamente na produção de AL, pois os microrganismos dependem do $\mathrm{pH}$ intra e extra celular, e este afeta a atividade catalítica das enzimas e o seu metabolismo desses seres (Mozzi et al., 2010). Nesse contexto, vários fatores 
são relatados para melhorar a eficácia da produção de AL em processos fermentativos BAL, entre eles está o controle do $\mathrm{pH}$. E apesar das BAL suportarem baixos valores de $\mathrm{pH}$ no meio fermentativo (Martinez et al., 2013), muitos pesquisadores concluíram que o controle do pH no processo fermentativo pode aumentar, significativamente, a produção de AL (AbdelRahman et al., 2013; Mi-Young et al., 2003; Moon et al., 2012). Porém, alguns métodos de controle de $\mathrm{pH}$, como a adição de agentes neutralizantes (Djukić-Vuković et al., 2012), podem afetar a produção de AL pelo aumento dos custos de purificação, causando consideráveis problemas ambientais (Martinez et al., 2013).

\subsection{Produção de Ácido Lático}

As maiores produções de AL foram obtidas a partir de meios de cultura com EL e fermentados por L. rhamnosus, plantarum e E. faecalis (Figura 3).

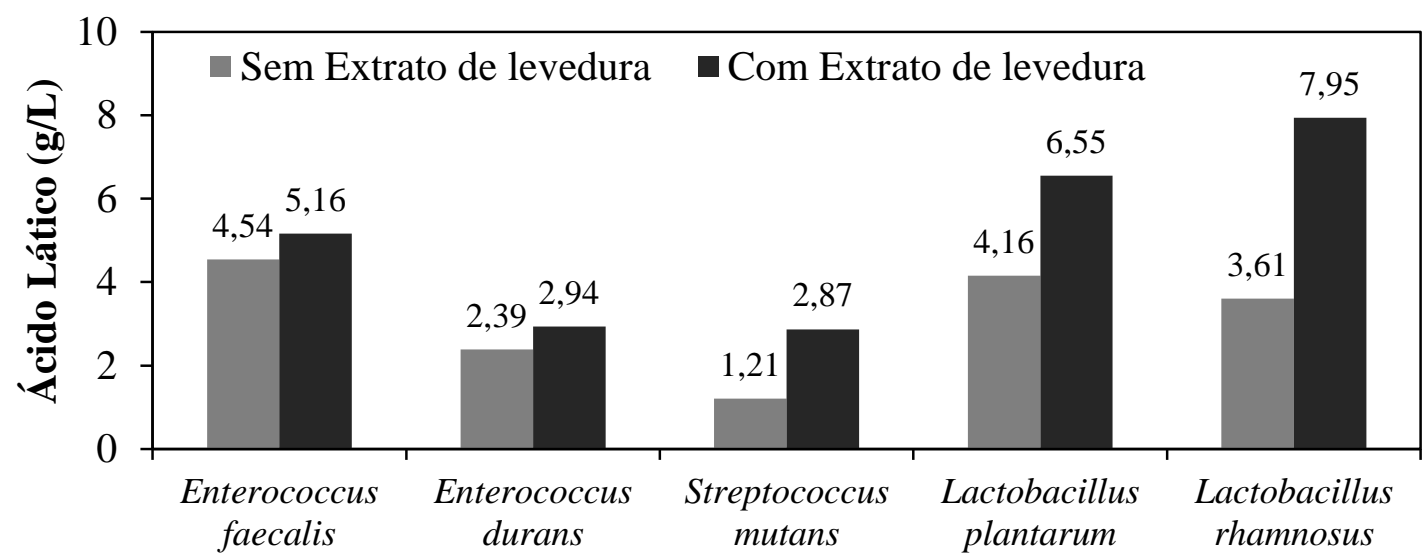

Figura 3 - Produção de ácido lático por bactérias láticas em meio de fermentação de polpa de batata hidrolisada adicionados ou não de extrato de levedura.

Os resultados obtidos neste trabalho elucidam a importância da suplementação do meio de polpa de batata com uma fonte de nitrogênio quando se visa à maior produção de AL. A adição de EL no meio de fermentação proporcionou o aumento de 3,6 para 7,95 g/L na produção de AL por L. rhamnosus (Figura 3). Segundo Mi-Young et al., (2003), o EL satisfaz as exigências nutricionais das BAL. Visto que esses microrganismos apresentam complexas exigências nutricionais para o seu desenvolvimento (Reddy et al., 2008), o enriquecimento exerce notadamente efeito positivo na produção de AL pelo aumento no consumo de AR, uma vez que é de conhecimento prévio que esses microrganismos obtêm energia por meio da fermentação de açúcares.

De acordo com as análises cromatográficas de quantificação de AL, verificou-se que a produtividade é aumentada quando há adição de EL no meio de fermentação. Após $96 \mathrm{~h}$ a maior produtividade $\left(0,08 \mathrm{~g} \cdot \mathrm{L}^{-1} \cdot \mathrm{h}^{-1}\right)$ foi alcançada por $L$. rhamnosus no meio com EL. No meio sem EL a maior produtividade foi de E. faecalis $\left(0,05 \mathrm{~g} \cdot \mathrm{L}^{-1} \cdot \mathrm{h}^{-1}\right)$. E. faecalis obteve a mesma produtividade $\left(0,05\right.$ g. $\left.\mathrm{L}^{-1} \cdot \mathrm{h}^{-1}\right)$ no meio com EL. Vários autores já relataram a importância do enriquecimento do meio de fermentação com uma fonte de nitrogênio, quando se utilizam BAL no processo, independente do substrato empregado (Altaf et al., 2011; Wee et al., 2004). Contudo, na Tabela 1 é possível notar que mesmo com menor produção de AL por E. faecalis em relação a L. rhamnosus (Figura 3), verifica-se que a adição de EL pouco 
influenciou na produtividade de AL pra E. faecalis. Tal resultado pode inferir diretamente nos custos de produção do AL, uma vez que este microrganismo dispensou o enriquecimento do meio nas condições testadas, o que consequentemente reduz os custos do processo.

\subsection{Viabilidade Celular}

Os inóculos iniciais da maioria dos meios de fermentação atingiram contagem entre $10^{7}$ e $10^{8}$ UFC.mL ${ }^{-1}$, e embora estes meios fermentativos tenham atingido baixos valores de $\mathrm{pH}$ e elevada acidez ao longo da fermentação, esses fatores não influenciaram na viabilidade celular final, visto que, os microrganismo elevaram em 1 ciclo logarítmico a contagem de células ou manteve a mesma que inicial ao final do processo em todos os meios fermentativos. Este fato é explicado pela alta tolerância das BAL a pH menor que 5 (Martinez et al., 2013), conferindo uma vantagem significativa na utilização desses microrganismos em processo fermentativos.. O uso de espécies que toleram baixo $\mathrm{pH}$ é importante, pois minimizam o uso de agentes tamponantes, reduzindo os custos e os problemas de poluição, além de facilitar os processos de recuperação do AL (John; Nampoothiri, 2008).

\section{CONCLUSÃO}

Com base nos resultados obtidos, conclui-se que a adição de EL no meio fermentativo hidrolisado de polpa de batata aumenta consideravelmente a produção de AL. Contudo, E. faecalis mostrou não ter seu metabolismo afetado pela adição de $5 \%$ de EL no meio fermentativo, tal comportamento pode influenciar diretamente os custos de produção de AL e propõe que esta espécie seja mais estudada a fim de testar novas condições a fim de reduzir os custos de produção.

A maior concentração final de AL foi de 7,95 g/L com produtividade de $0,08 \mathrm{~g} \cdot \mathrm{L}^{-1} \cdot \mathrm{h}^{-1}$ após $96 \mathrm{~h}$ de fermentação a $37^{\circ} \mathrm{C}$ sem agitação por L. rhamnosus. A viabilidade celular dos microrganismos não foi influenciada pelas condições fermentativas testadas.

\section{REFERÊNCIAS}

ABDEL-RAHMAN, M. A.; TASHIRO, Y.; SONOMOTO, K. Recent advances in lactic acid production by microbial fermentation processes. Biotechnol Adv, v. 31, n. 6, p. 877-902, 2013.

ALTAF, M. D. et al. Single step fermentation of starch to L (+) lactic acid by Lactobacillus amylophilus GV6 in SSF using inexpensive nitrogen sources to replace peptone and yeast extract - Optimization by RSM. Process Biochem., v. 41, p. 465-472, 2011.

ALTAF, M.; NAVEENA, B. J.; REDDY, G. Use of inexpensive nitrogen sources and starch for $\mathrm{L}(+)$ lactic acid production in anaerobic submerged fermentation. Bioresour Technol, v. 98, n. 3, p. 498-503, 2007.

AOAC INTERNATIONAL. Official Methods of Analysis of AOAC International. 19. th. ed. Chicago: Pharmaboocks, 2012.

DJUKIĆ-VUKOVI Ć, A. P. et al. Effect of different fermentation parameters on L -lactic acid production from liquid distillery stillage. Food Chem, v. 134, p. 1038-1043, 2012. 
EVANGELISTA, R. M. et al. Qualidade nutricional e esverdeamento pós-colheita de tubérculos de cultivares de batata. Pesq Agropecuária Bras, v. 46, n. 8, p. 953-960, 2011.

INSTITUTO ADOLFO LUTZ. Métodos físico-químicos para análise de alimentos. 4. ed. São Paulo: Instituto Adolfo Lutz, 2008.

INSTITUTO BRASILEIRO DE GEOGRAFIA E ESTATÍSTICA. Batata. São Paulo: IBGE, 2013. Disponível em: <http://www.agricultura.mg.gov.br/ index.php?option =com_content \&view=article\&id=1361\&Itemid=29>. Acesso em: 20 out. 2013.

JOHN, R. P.; NAMPOOTHIRI, K. M. Strain improvement of Lactobacillus delbrueckii using nitrous acid mutation for l-lactic acid production. World J Microbiol Biotechno., v. 24, n. 12, p. 3105-3109, 2008.

JOHN, R. P.; NAMPOOTHIRI, K. M.; PANDEY, A. Fermentative production of lactic acid from biomass: an overview on process developments and future perspectives. Appl Microbiol Biotechnol, v. 74, n. 3, p. 524-34, 2007.

LIMA, C. J. B. et al. Response surface optimization of D(-)-lactic acid production by Lactobacillus SMI8 using corn steep liquor and yeast autolysate as an alternative nitrogen source. African J Biotechnol, v. 8, n. 21, p. 5842-5846, 2009.

MARTINEZ, F. A. C. et al. Lactic acid properties, applications and production: A review. Trends Food Sci Technol., v. 30, n. 1, p. 70-83, 2013.

MI-YOUNG, H. et al. Kinetics analysis of growth and lactic acid production in $\mathrm{pH}$-controlled batch cultures of Lactobacillus casei KH-1 using yeast Extract / corn Steep liquor / glucose medium. J Biosci Bioeng, v. 96, n. 2, p. 134-140, 2003.

MOON, S.; WEE, Y.; CHOI, G. A novel lactic acid bacterium for the production of high purity L-lactic acid, Lactobacillus paracasei subsp. paracasei CHB2121. J Biosci Bioeng, v. 114, n. 2, p. 155-159, 2012.

MOZZI, F.; RAYA, R. R.; VIGNOLO, G. M. Biotechnology of lactic acid bacteria: novel applicattions. Ames: Blackwell, 2010.

NELSON, N. A photometric adaptation of the Somogyi method for the determination of glucose. J Biol Chem, v. 153, p. 375-380, 1944.

NÚCLEO DE ESTUDOS E PESQUISAS EM ALIMENTOS. Tabela brasileira de composição de alimentos. 2. ed. Campinas: NEPA, 2006.

OLIVEIRA, R. F. et al. Produção fermentativa de ácido lático a partir do melaço da cana-deaçúcar por Lactobacillus casei. Brazilian J Food Technol, v. 7, p. 34-40, 2009.

PAVLAK, M. C. DE M.; ABREU-LIMA, T. L. DE; CARREIRO, S. C. Estudo da fermentação do hidrolisado de batata doce utilizando diferentes linhagens de Saccharomyces cerevisiae. Quím Nova, v. 34, n. 1, p. 82-86, 2011.

PLATA-OVIEDO, M. S. Secagem do amido fermentado de mandioca: modificação química relacionada com propriedade de expansão e características físico-químicas. Campinas, SP: Universidade Estadual de Campinas, 1998.

PEREIRA, A. S. Batata: fonte de alimento para a humanidade. Hortic Bras, v. 26, n. 1, p. 133-133, 2008. 
REDDY, G. et al. Amylolytic bacterial lactic acid fermentation - A review. Biotechnol. $A d v$. , v. 26, p. 22-34, 2008.

SALMINEN, S.; VON WRIGHT, A.; OUWEHAND, A. (Eds.). Lactic acid bacteria microbiological and functional aspects. 3. ed. New York: Marcel Dekker, Inc., 2004.

TAVARES, V. B. Silagens de capim-elefante aditivadas com raspa de batata diversa na alimentação de bovinos leiteiros. Lavras: Universidade Federal de Lavras, 2009.

TEBALDI, V. M. R. et al. Avaliação microbiológica de bebidas lácteas fermentadas adquiridas no comércio varejista do sul de Minas Gerais. Ciência e Tecnol de Aliment, v. 31, n. 4, p. 1085-1088, 2007.

VIJAYAKUMAR, J.; ARAVINDAN, R.; VIRUTHAGIRI, T. Recent trends in the production, purification and application of lactic acid. Chem. Biochem. Eng. Q., v. 2, p. 245264, 2008.

WEE, Y.-J.; KIM, J. -N.; YUN, J. -S.; RYU, H -W. Utilization of sugar molasses for economical L(+)-lactic acid production by batch fermentation of Enterococcus faecalis. Enzyme Microb. Technol., v. 35, n. 6-7, p. 568-573, dez. 2004.

\section{AGRADECIMENTOS}

A FAPEMIG pelo financiamento e auxílio para participação no evento, à CAPES pela bolsa de Mestrado e à Fundação Oswaldo Cruz/RJ pela doação dos microrganismos. 